\title{
Structural Analysis of Open-Column Fractionation of Peracetic Acid-Treated Kraft Lignin ${ }^{1}$
}

\author{
Se-Yeong $\mathrm{PARK}^{2}$ - June-Ho $\mathrm{CHOI}^{3}$ - Seong-Min $\mathrm{CHO}^{3}$ • \\ Joon Weon $\mathrm{CHOI}^{4,5} \cdot$ In-Gyu CHOI (i) ${ }^{6,7, \dagger}$
}

\begin{abstract}
This study investigates the selective fractionation of lignin with uniform structures and lower molecular weight. Lignin solubilization was first performed using a solution of acetic acid (AA) and hydrogen peroxide (HP) (4:1, (v/v)) to form peracetic acid (PAA), which is a strong oxidant. After the PAA-induced solubilization that occurred at $80^{\circ} \mathrm{C}$, totally soluble lignin was extracted by ethyl acetate (EA) and divided into organic- and water-soluble fractions. The EA fraction was then fractionated by open-column using three solutions (chloroform-ethyl acetate, methanol, and water) sequentially. With an increase in the solvent polarity during the fractionation step, the molecular weight of the lignin-derived compounds in the fraction increased. Remarkably, some lignin fractions did not have aromatic structures. These fractions were identified as carboxylic acid-containing polymers like poly-carboxylates. These results conclude that the selective production of lignin-derived polymers with specific molecular weight and structural characteristics could be possible through open-column fractionation.
\end{abstract}

Keywords: lignin solubilization, peracetic acid treatment, column fractionation, lignin application

\section{INTRODUCTION}

Lignin has been produced through various processes using lignocelluosic biomass, which are readily available in large amounts. Lignin has aromatic ring struc- tures chemically, and thus it has been considered potentially as promising raw materials. In general, the method of isolating lignin from lignocellulosic biomass can be a acrucial factor in consideration of its end-uses (Ragauskas et al., 2014; Strassberger et al.,

${ }^{1}$ Date Received July 5, 2020, Date Accepted August 10, 2020

2 Department of Forest Biomaterials Engineering, College of Forest and Environmental Science, Kangwon National University, Chuncheon, Gwangwon-do 24341, Republic of Korea

${ }^{3}$ Department of Forest Sciences, College of Agriculture and Life Sciences, Seoul National University, Seoul 08826, Republic of Korea

${ }^{4}$ Institute of Green-Bio Science and Technology, Seoul National University, Pyeongchang, Gangwon-do 25354, Republic of Korea

${ }^{5}$ Graduate School of International Agricultural Technology, Seoul National University, Pyeongchang, Gangwon-do 25354, Republic of Korea

${ }^{6}$ Department of Agriculture, Forestry and Bioresources, College of Agriculture and Life Sciences, Seoul National University, Seoul 08826, Republic of Korea

${ }^{7}$ Research Institute of Agriculture and Life Sciences, College of Agriculture and Life Sciences, Seoul National University, Seoul 08826, Republic of Korea

$\dagger$ Corresponding author: In-Gyu CHOI (e-mail: cingyu@snu.ac.kr, ORCID: 0000-0001-5604-6823) 
2014). Most of lignin are produced in paper and pulp industries, and further processes for making the lignin as value-products have been attempted to improve economic value (Doherty et al., 2011; Kim et al., 2017; Lee et al., 2019; Leskinen et al., 2015).

Among commercial lignins, kraft lignin in black liquor is a commonly used as energy sources in kraft puling process. Despite the variety of availability, the utilization of kraft lignin is restricted by condensed inter-unit linkages due to a complex degradation and condensation during the pulping process. In addition, use of the lignin is limited by its structural diversity in terms of high polydispersity and non-uniform reactivity. Besides, different functional groups in kraft lignin make its utilization quite challenging (Jiang et al., 2016; Vishtal and Kraslawski, 2011).

Several techniques have been introduced to obtain and separate the lignin with uniform properties. For example, selective precipitation based on $\mathrm{pH}$ has been conducted by adding acidic agents such as sulfuric and hydrochloric acids (Helander et al., 2013; Lourencon et al., 2015; Sun et al., 1999; Zhu et al., 2015). Ultrafiltration is one technique for separating lignin compounds based on molecular cut-off. It has sparked great interests in several fields such as chemical, biological, and pharmaceutical industries (Humpert et al., 2016; Toledano et al., 2010). However, each method has its own disadvantages, such as low purity, and high cost associated with filtration.

Organic solvent extraction or fractionation has been considered a promising method and efficient and economical process for lignin fractionation; it has powerful advantages for separating lignin compounds according to definite molecular weight and functionality. Based on these advantages, many studies have already been conducted using this technique over the last few decades (Helander et al., 2013; Jiang et al., 2016; Kim et al., 2017; Li et al., 2012; Park et al., 2018; Thring et al., 1996; Wang et al, 2010). Lignin fractionation with organic solvents is typically performed by liquid-liquid phase separation using a solid lignin sample as a starting material. Although the technique has gained much attention, it has limited applicability in bulk processing.

In this study, open-column fractionation was used to improve existing techniques, and fractionate lignin compounds according to their molecular weight and functionality. Open-column chromatography is a simple method that is widely used to isolate certain chemicals as value-added products. This technique has some advantages; it can easily eliminate contaminants from the sample, and low-cost silica-gel is used as a typical stationary. Thus, it can improve process efficiency in terms of price competitiveness. Before the column-fractionation, lignin solubilization using peracetic acid (PAA) was first conducted. PAA is a promising oxidant for dissolving lignin and deconstructing its structures, which has widely applied to bio-refinery fields. In our previous papers, it demonstrated the effect on lignin degradation and changing solubility, and proposed the total utilization processes of lignocellulosic biomass using the PAA (Choi et al., 2019; Park et al., 2019; Park et al., 2020). Based on the results from previous studies, we attempted a study to facilitate the selective use of lignin.

\section{MATERIALS and METHODS}

\subsection{Materials}

Kraft lignin (KL, hardwood) was provided by Moorim P\&P Co. and it was used as a starting materials. Chemical composition of the KL is described in Table 1.

\subsection{Peracetic acid treatment}

KL (approximately $1 \mathrm{~g}$ ) was put into a glass bomb and dissolved in $30 \mathrm{~mL}$ of a solution of acetic acid 
Table 1. Chemical composition of kraft lignin used in this study

\begin{tabular}{cc}
\hline Total lignin content (\%) & $94.1(0.61)$ \\
\hline \hline Klason lignin (\%) & $87.4(0.93)$ \\
Acid soluble lignin (\%) & $6.7(0.32)$ \\
Ash (\%) & $2.9(0.13)$ \\
Carbohydrate (\%) & $1.9(0.07)$ \\
$\mathrm{M}_{\mathrm{w}}($ Daltons) & 2,813 \\
$\mathrm{M}_{\mathrm{w}}$ (Daltons) of acetylated lignin & 4,068 \\
$\mathrm{C}(\mathrm{wt} \%)$ & 59.7 \\
$\mathrm{H}(\mathrm{wt} \%)$ & 5.3 \\
$\mathrm{O}(\mathrm{wt} \%)$ & 31.2 \\
$\mathrm{~N}(\mathrm{wt} \%)$ & 0.4 \\
$\mathrm{~S}(\mathrm{wt} \%)$ & 3.3 \\
\hline
\end{tabular}

${ }^{1}$ By difference

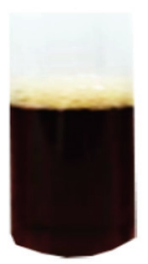

\section{Reaction with} PAA for $1 \mathrm{~h}$

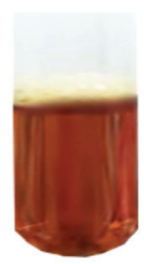

Fig. 1. The color changes from kraft lignin to solubilized lignin after PAA treatment.

(AA, 98\%) and hydrogen peroxide (HP, 30\%) at 4:1 $(\mathrm{v} / \mathrm{v})$ for the reaction. The solution was titrated using the procedure referred by our previous paper (Park et al., 2020). It contained $1.5 \%$ of PAA and $5.8 \%$ of HP, respectively. The PAA treatment was conducted at $80^{\circ} \mathrm{C}$ for $1 \mathrm{~h}$ using a dry block (MG-2200, EYELA, Japan). After the reaction, the completely liquefied sample (Fig. 1) was obtained and diluted with 10-fold with distilled water to adjust the $\mathrm{pH}$ to 2 . The diluted liquid was extracted twice with $300 \mathrm{~mL}$ of ethyl acetate (EA). For further fractionation processes, solvent was removed using a rotary evaporator at $40^{\circ} \mathrm{C}$, and the remaining solute was freeze-dried. The residual aqueous fraction, which was not extracted by EA, was also freeze-dried.

\subsection{Fractionation of liquefied lignin}

The EA-soluble products in KL were fractionated using open-column chromatography system to separate the lignin fractions; $20 \mathrm{~g}$ of silica gel was used as a stationary phase and chloroform $\left(\mathrm{CHCl}_{3}\right)$ was poured into a glass tube $(2.8-\mathrm{cm}$ inner-diameter). Then, the EA-soluble products (dissolved in $4 \mathrm{~mL}$ of EA) were added to the column. The solvent fractionation was conducted using $200 \mathrm{~mL}$ of $\mathrm{CHCl}_{3}$-EA $(2: 1, \mathrm{v} / \mathrm{v})$, methanol $(\mathrm{MeOH})$, and distilled water $\left(\mathrm{H}_{2} \mathrm{O}\right)$, successively. After fractionation, each fraction was evaporated to remove the solvent and freeze-dried for further analysis. The overall process and nomenclature for each fraction is as shown in Fig. 2.

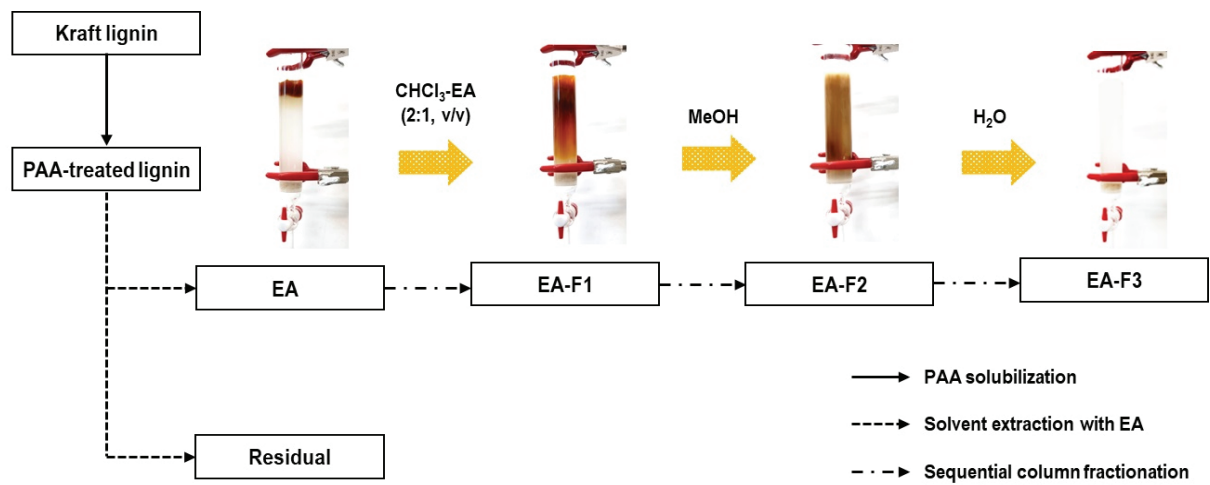

Fig. 2. Scheme of the overall lignin solubilization and column fractionation. 
- EA: Ethyl acetate fraction

- EA-F1: EA fractionated with chloroform:ethyl acetate $(2: 1, \mathrm{v} / \mathrm{v})$

- EA-F2: EA fractionated with methanol

- EA-F3: EA fractionated with water

- Residual: Residual aqueous fraction

\subsection{Characterization of lignin fractions}

\subsubsection{Gel permeation chromatography (GPC) \\ GPC was performed to analyze the molecular} weight of the lignin. Acetylation was conducted before GPC analysis to improve the solubility of the solid samples. The solid samples were acetylated with pyridine and acetic anhydride $(1: 1, \mathrm{v} / \mathrm{v})$ at $105^{\circ} \mathrm{C}$ for $2 \mathrm{~h}$. After acetylation, the reacted solid was obtained by dropping the water and centrifuged. The molecularweight distribution and polydispersity index (PDI) of the acetylated samples from each fraction was determined by GPC using a 1260 Infinity II refracting index detector (Agilent Technologies, Santa Clara, CA, USA) equipped with a PLgel5 $\mu \mathrm{m}$ MIXED-C column $\left(300 \times 7.5 \mathrm{~mm}^{2}\right.$, VARIAN). The rate of mobile phase (THF) flow was set at $1 \mathrm{~mL} / \mathrm{min}$. and the sample injection volume was $20 \mu \mathrm{L}$. Molecular weight calibration was carried out using several polystyrene standards. The range was from 266 to 60,000 Daltons.

\subsubsection{Carbon-13 nuclear magnetic resonance $\left({ }^{13} \mathrm{C}-\mathrm{NMR}\right)$}

The types of carbon linkages of each lignin fraction were investigated by conducting ${ }^{13} \mathrm{C}$-NMR analysis. About $60-80 \mathrm{mg}$ of each solid sample were dissolved in $0.6 \mathrm{~mL}$ of dimethyl sulfoxide- $d_{6}$ (DMSO- $d_{6}$, Sigma Aldrich Co.). Deuterium oxide $\left(\mathrm{D}_{2} \mathrm{O}\right)$ was used as a solvent samples, which did not dissolve in DMSO- $d_{6}$. NMR data was recorded at $60^{\circ} \mathrm{C}$ for $8 \mathrm{~h}$ using a spectrometer set to $600 \mathrm{MH}_{\mathrm{z}}$ (ADVANCE 600, Bruker, Germany).

\subsubsection{Fourier-transform infrared spectroscopy ( $F T-I R)$}

The structural differences between fractions were compared by performing FT-IR analysis. FT-IR spectra were obtained using a Nicolet 6700 spectrometer (Thermo Scientific, USA). For each sample, 32 scans were recorded in 4,000-650 $\mathrm{cm}^{-1}$ spectral range at a $8 \mathrm{~cm}^{-1}$ resolution. Spectral data were collected with OMNIC 9.2 (Thermo Fisher Scientific Inc. USA) software.

\section{RESULTS and DISCUSSION}

\subsection{Yield of each lignin fraction}

Totally liquefied KL after PAA treatment was extracted by EA to divide into organic and water-soluble fractions. As shown in Table 2, the yield of the EA fraction was $57.9 \%$, and this fraction was sequentially fractionated followed by $\mathrm{CHCl}_{3}$-EA (EA-F1), $\mathrm{MeOH}$ (EA-F2), and $\mathrm{H}_{2} \mathrm{O}$ (EA-F3). Meanwhile, significant

Table 2. The yields of each fraction obtained by solvent extraction and open-column fractionation

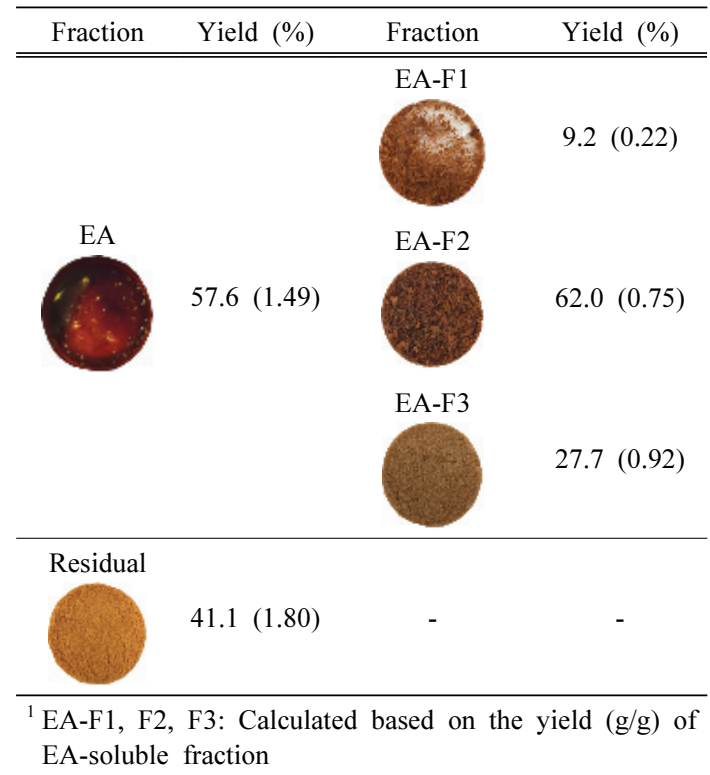


$K L$

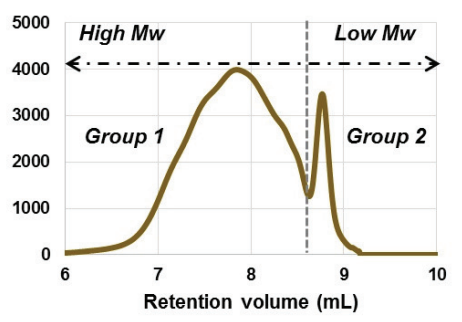

EA

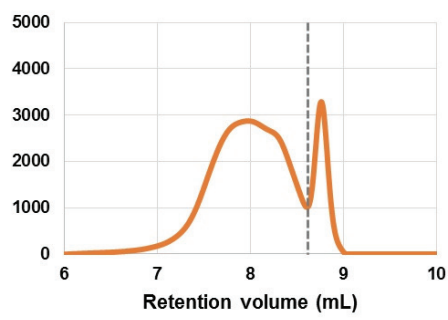

Residual

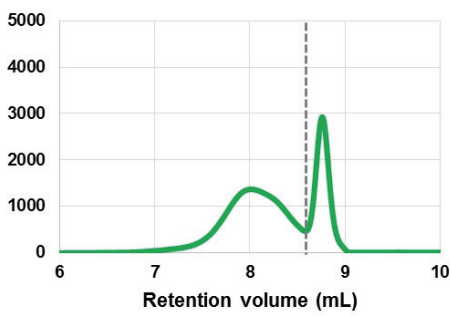

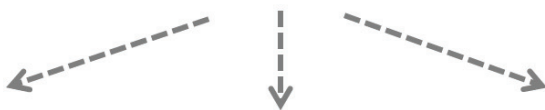

EA-F2
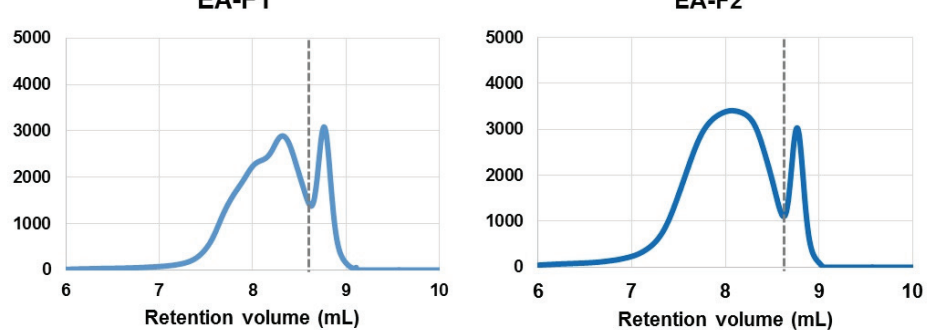

EA-F3

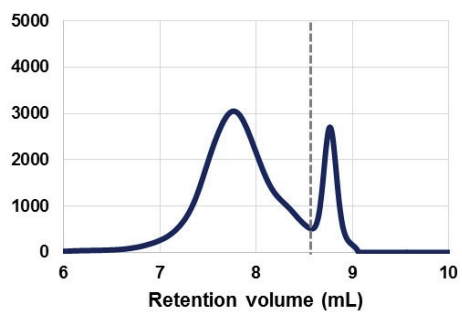

Fig. 3. Chromatograms of molecular weight for each fraction.

amounts, $41.1 \%$ yield, of residual aqueous fraction (Residual) were obtained after PAA treatment.

The yields of the three fractions obtained from EA-soluble compounds were shown in Table 2, and EA-F2 showed the highest yields (62.0\%) among them. Interestingly, EA-F2 and EA-F3 obtained from EA-soluble fractions were not dissolved in EA after column fractionation due to structural changes in the two fractions after PAA treatment.

\subsection{Molecular weight distribution}

Solvent extraction and column fractionation were performed in this study to fractionate the PAA-treated lignin with different molecular weight and characteristics. All fractions exhibit bimodal molecular weight curves as shownin Fig. 3, which meant that lignin-derived molecules were present with specific molecular weight ranges, collectively.
Table 3 shows the molecular weight values of all fractions. The $M_{w}$ of all fractions (acetylated) was significantly decreased compare tothat of untreated KL (4,068 Da). The $\mathrm{M}_{\mathrm{w}}$ of EA and Residual fractions were 2,075 and 1,221 Da, respectively. Meanwhile, chloroform, ethyl acetate and methanol were used to sequentially fractionate EA soluble products. The $\mathrm{Mw}$ and polydispersity index (PDI) of the three fractions increased in proportion to the solvent polarity increase as shown in Table 3. These tendencies were similar to those of previous studies, and it has been reported that when polar solvents, such as methanol, and acetone, were used for fractionation, the molecular weight and PDI increased (2013; Kim et al., 2017; Li et al., 2012; Park et al., 2018; Thring et al., 1996; Wang et al, 2010). Solubility and hydrogen bonding parameters of the solvents used in study are presented in Table 4 (Sameni et al., 2017).

As described in above, molecular weight and PDI 
Se-Yeong PARK $\cdot$ June-Ho CHOI $\cdot$ Seong-Min CHO $\cdot$ Joon Weon CHOI $\cdot$ In-Gyu CHOI

Table 3. Molecular weight (Dalton) distribution of each fraction

\begin{tabular}{|c|c|c|c|c|c|c|c|c|c|c|c|c|}
\hline & \multicolumn{12}{|c|}{ Broad } \\
\hline & \multicolumn{2}{|c|}{$\mathrm{KL}$} & \multicolumn{2}{|c|}{ EA } & \multicolumn{2}{|c|}{ EA-F1 } & \multicolumn{2}{|c|}{ EA-F2 } & \multicolumn{2}{|c|}{ EA-F3 } & \multicolumn{2}{|c|}{ Residual } \\
\hline $\mathrm{Mw}$ & \multicolumn{2}{|c|}{4068} & \multicolumn{2}{|c|}{2075} & \multicolumn{2}{|c|}{1366} & \multicolumn{2}{|c|}{2075} & \multicolumn{2}{|c|}{3031} & \multicolumn{2}{|c|}{1221} \\
\hline $\mathrm{Mn}$ & \multicolumn{2}{|c|}{1072} & \multicolumn{2}{|c|}{803} & \multicolumn{2}{|c|}{635} & \multicolumn{2}{|c|}{868} & \multicolumn{2}{|c|}{976} & \multicolumn{2}{|c|}{543} \\
\hline \multirow[t]{4}{*}{ PDI } & \multicolumn{2}{|c|}{3.79} & \multicolumn{2}{|c|}{2.58} & \multicolumn{2}{|c|}{2.15} & \multicolumn{2}{|c|}{2.39} & \multicolumn{2}{|c|}{3.11} & \multicolumn{2}{|c|}{2.25} \\
\hline & \multicolumn{12}{|c|}{ Separated } \\
\hline & \multicolumn{2}{|c|}{ KL } & \multicolumn{2}{|c|}{ EA } & \multicolumn{2}{|c|}{ EA-F1 } & \multicolumn{2}{|c|}{ EA-F2 } & \multicolumn{2}{|c|}{ EA-F3 } & \multicolumn{2}{|c|}{ Residual } \\
\hline & 1 & 2 & 1 & 2 & 1 & 2 & 1 & 2 & 1 & 2 & 1 & 2 \\
\hline Mw & 4427 & 266 & 2425 & 270 & 1570 & 261 & 2307 & 275 & 3552 & 274 & 1702 & 268 \\
\hline $\mathrm{Mn}$ & 1749 & 255 & 1356 & 261 & 987 & 252 & 1329 & 267 & 2078 & 265 & 1201 & 261 \\
\hline PDI & 2.53 & 1.04 & 1.79 & 1.03 & 1.59 & 1.04 & 1.74 & 1.03 & 1.71 & 1.03 & 1.42 & 1.03 \\
\hline Area $(\%)^{1}$ & 88.5 & 11.5 & 82.5 & 17.5 & 79.4 & 20.6 & 86.6 & 13.4 & 83.3 & 16.7 & 65.7 & 34.3 \\
\hline
\end{tabular}

${ }^{1}$ Relative area (\%) calculated by dividing 1 and 2 groups based on retention volume at $8.6 \mathrm{~mL}$

Table 4. Solubility parameter ( $\delta$ - from Hildebrand theory) and hydrogen bonding parameter ( $\delta$ h- from Hansen Theory) of solvents and water used in this study (Sameni et al., 2017)

\begin{tabular}{cccc}
\hline No. & Solvent & $\delta\left(\mathrm{cal} / \mathrm{cm}^{3}\right)$ & $\delta_{\mathrm{h}}\left(\mathrm{cal} / \mathrm{cm}^{3}\right)^{1 / 2}$ \\
\hline \hline 1 & Chloroform & 9.2 & 2.8 \\
2 & Ethyl acetate & 9.1 & 3.5 \\
3 & Methanol & 14.3 & 10.9 \\
4 & Water & 23.5 & 20.6 \\
\hline
\end{tabular}

of all fractions were divided into Group 1 and 2 based on the median value of $8.6 \mathrm{~mL}$ (Fig. 3). In addition, the relative quantitative percentages were calculated by dividing the entire area by the median value. As can be seen from the results at the bottom of Table 3 , it was expected that Group 2 in the diagram would consist of low-molecular weight compounds in the range of 261 275 Da. However, Group 1 was observed as relatively high-molecular weight lignins, while PDI was significantly decreased compared to untreated KL. In particular, Group 1 of the EA-F2 fraction was mainly comprised of high weight molecules, which accounted for $87 \%$ of the entire area.

It is important to have a uniform structure for lignin application, and thus PDI is considered an important criterion. Among the fractions, the Residual fraction showed the lowest PDI in Group 1. However, since the portion of Group 1 was the lowest at $66 \%$, the separation of the each group according to molecular weight may be necessary to use those that have narrow molecular weight distribution.

\subsection{Structural analysis}

\subsection{1. ${ }^{13} \mathrm{C}-\mathrm{NMR}$}

The carbon bond types ofKL and their fractions, obtained by solvent extraction and column fractionation, were investigated by performing ${ }^{13} \mathrm{C}-\mathrm{NMR}$ analysis. At 100-150 ppm as shown in Fig. 4, carbon signals originating from aromatic structure; which included symmetric carbons in syringyl units, etherified carbons in guaiacyl units and non-etherified carbons; were typically observed. Meanwhile, C- $a, \mathrm{C}-\beta, \mathrm{C}-\gamma$ carbons in $\beta$-O-4 were observed around at around 58-100 ppm. In addition, a strong peak at $55 \mathrm{ppm}$ indicated a typical carbon signal from the methoxy group $\left(-\mathrm{OCH}_{3}\right)$ in the lignin structure. At $151-200 \mathrm{ppm}$, the $\mathrm{C}=\mathrm{O}$ signals of carboxylic and carbonyl groups in 


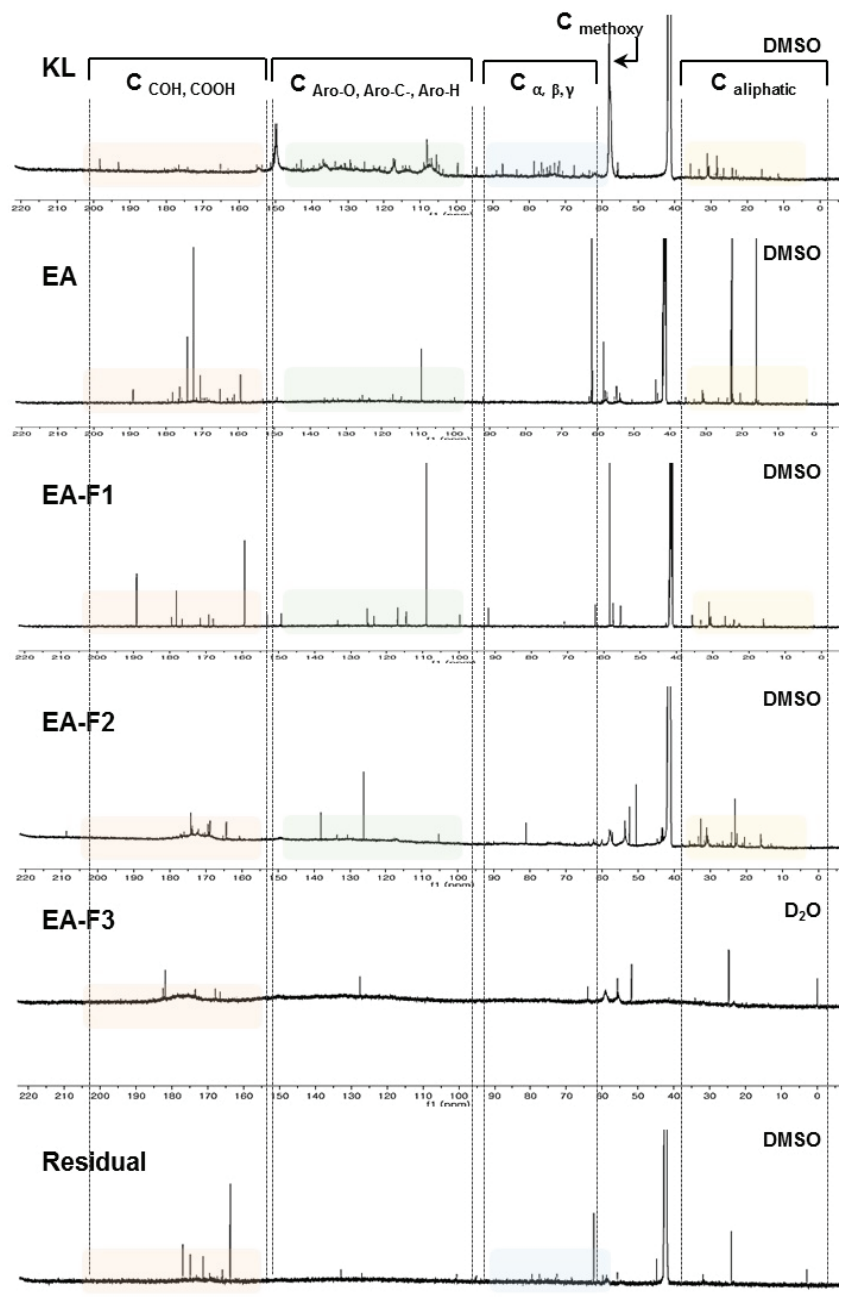

Fig. 4. The ${ }^{13} \mathrm{C}-\mathrm{NMR}$ spectra of $\mathrm{KL}$ and its fraction.

aromatic and aliphatic structures structures were also observed (Capanema et al., 2004; Chen and Robert, 1988; Mörck et al., 1986; Terashima et al., 2002; Wen et al., 2013). Based on these results, the carbon signal patterns of each fraction were compared.

Untreated KL showed diverse carbon signals in all spectral regions. In particular, carbons were clearly observed in aromatic structures of lignin. In addition, aryl-ether-linked carbon signals at 55-100 ppm and aliphatic carbons were also commonly observed. KL was generated bythe kraft pulping process, which made lignin structures more condensed compared to natural lignin in wood because the process needs a comparatively high temperature. However, aryl-etherlinked carbons were maintained at 55-100 ppm. Meanwhile, EA and Residual fractions were obtained after PAA solubilization, and these fractions showed simple peaks compared to KL. In particular, the number of 
carbons related to the aromatic structure and those of aryl-ether-linked carbons were clearly decreased; these can explain how PAA cleaved the linkage of lignin structures and produced less-complex lignin-derived compounds.

Meanwhile, three fractions obtained by open-column fractionation using EA-soluble compounds showed significant differences between each fraction. In particular, the EA-F3 fraction did not show carbon signals originating from aromatic structures in lignin. Only few signals were observed at 151-200 ppm, which means that compounds in the EA-F3 fraction may not have contained aromatic compounds.

Intensive signals of $\mathrm{C}=\mathrm{O}$ from carboxylic or carbonyl group were observed in all fractions; these functional groups can be involved in solubility. As the lignin moieties containing methoxyl group conjugate bonds decreased, the compounds became hydrophilic substances. According to previous research, PAA solution can result in demethoxylation of the lignin structure. Therefore, some fractions did not dissolve in organic solvents due to changes in the functional groups.

\subsection{2. $F T-I R$}

Fig. 5 shows the FT-IR spectra of each fraction obtained by solvent extraction and fractionation. At the top of the spectra, KL indicates typical untreated lignin assignment and its spectrum was used as a reference for comparison with other fractions. The bands for aromatic skeleton vibrations were at 1598, 1513, $1455 \mathrm{~cm}^{-1}$, included $\mathrm{C}=\mathrm{C}$. In addition, $\mathrm{C}-\mathrm{O}$ bands related to ether bonds in syringyl and guaiacyl groups were also observed at $1400-1000 \mathrm{~cm}^{-1}$. The band assignments were similar to typical peaks related to lignin structure that are mentioned in previous studies.
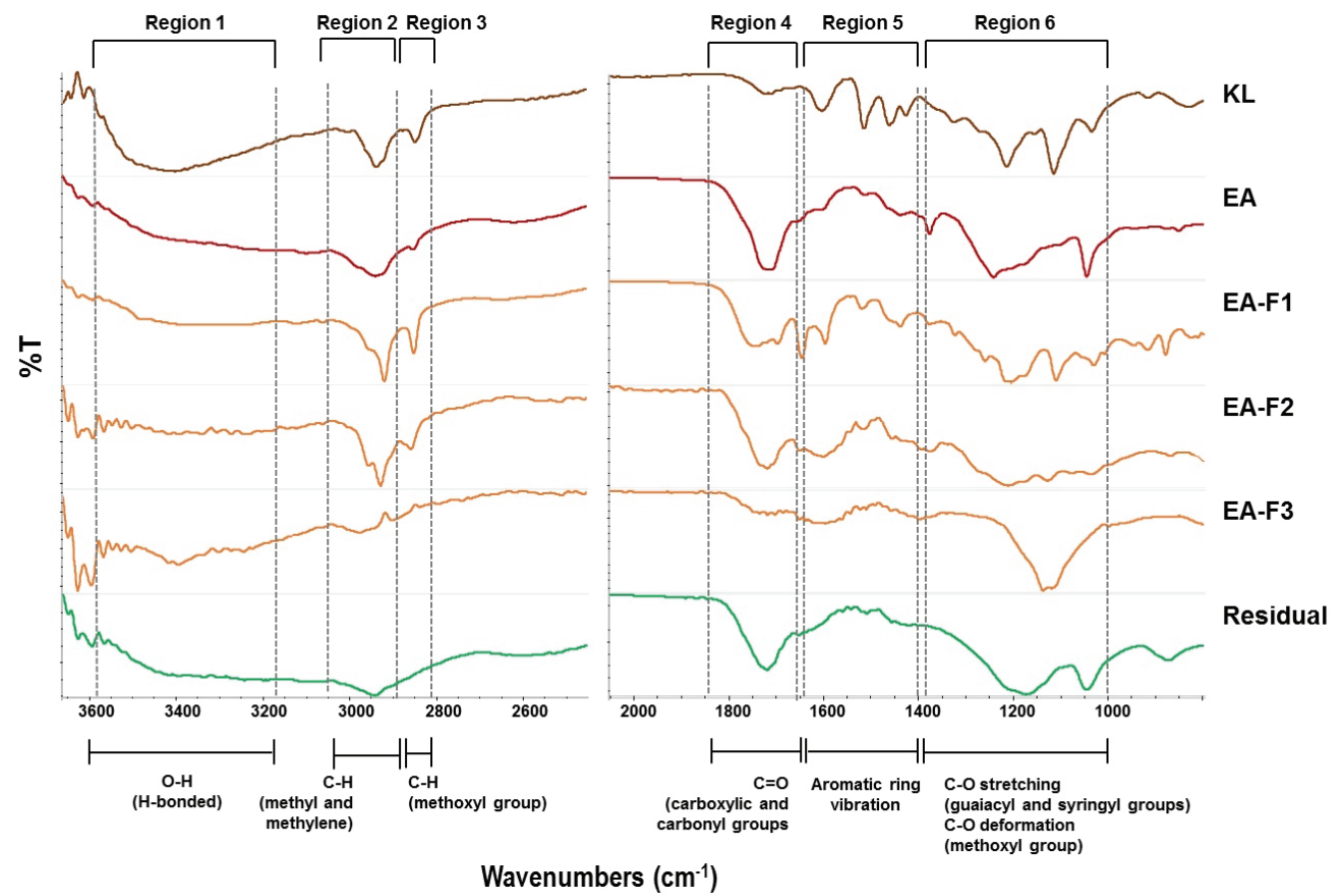

Fig. 5. The FT-IR spectra of each fraction obtained after solvent extraction and column fractionation. 
At around $1660-1800 \mathrm{~nm}$, the strong bands indicated that $\mathrm{C}=\mathrm{O}$ peaks originated from the carboxylic acid carbonyl groups that were present in organic polymers (Lisperguer et al., 2009; Sills and Gossett, 2012; Zhou et al., 2011). EA-soluble compounds obtained by solvent extraction after PAA treatment were sequentially fractionated by the column. Interestingly, there was no peak related to the aromatic skeleton from lignin in the EA-F3 fraction. Furthermore, the intensity of the $\mathrm{C}=\mathrm{O}$ bands was also decreased in the EA-F3 fraction; these corresponded to the ${ }^{13} \mathrm{C}$-NMR results that also showed that no carbon signal was involved the aromatic structures.

Meanwhile, the Residual fraction showed a simple spectrum pattern compared to other fractions, and this was similar to the patterns of poly-carboxylate polymers. The signal at near $1700 \mathrm{~cm}^{-1}$ proves the existence of ester bonds; the peaks at around $1400 \mathrm{~cm}^{-1}$ represent for $-\mathrm{CH}_{2}-$, and the signal at $1100 \mathrm{~cm}^{-1}$, proved that it was similar to the poly-carboxylate-type molecular structure (Mohamed et al., 2016; Zhang et al., 2014). Recently, our research reported that water-soluble lignin obtained by PAA treatment shows better performance on cement fluidity compared to commercial plasticizers (lignosulfonate and polycarboxylate ether) (Kim et al., 2020). As such, the Residual fraction has similar structural characteristics to polycarboxylate, which was probably due to PAA oxidation accompanied by carbonyl, hydroxyl, and methoxyl groups changes.

Among the fractions, EA-F3 and the Residual fractions were well-dissolved in water as mentioned in previous results. In particular, the peaks originating from $\mathrm{CH}_{2}$ and $\mathrm{CH}_{3}$ at $3000-2800 \mathrm{~cm}^{-1}$ were not observed in those fractions, which was evidence of demethoxylation by PAA. In other words, it is expected that the lignin-derived products in the two fractions were dissolved in water due to the change of the functional group.

\section{CONCLUSION}

Open-column fractionation was performed using several solvents to fractionate kraft lignin-derived compounds according to their molecular weight and chemical properties. Before column fractionation, PAA treatment was first carried out to dissolve and depolymerize the lignin, showing more uniform structures and changes of its functionality. After open-column fractionation, lignin in each fraction showed different molecular ranges and structures. In particular, lignin in some fractions (EA-F3 and Residual) that were dissolved in water did not show the original aromatic skeleton of lignin structure. It seemed that PAA-induced lignin dissolution, degradation and also structural changes with a large amount of carboxylic acid groups. In summary, combination of PAA solubilization and open-column fractionation could have a simultaneous effect on the deconstruction, low-molecularization of lignin and also separation of lignin-derived compounds according to their molecular weight range and structures. Based on these results, it was concluded that many problems related to complexity and heterogeneity of lignin could be improved through these techniques.

\section{ACKNOWLEDGMENT}

This work was supported by National Research Foundation Korea (NRF) grant funded by the Korea Government (MSIT) (2019R1A2C1005369).

\section{REFERENCES}

Capanema, E.A., Balakshin, M.Y., Kalda, J.F. 2004. A comprehensive approach for quantitative lignin characterization by NMR spectroscopy. Journal of Agricultural and Food Chemistry 52(7): 1850-1860. 
Chen, C.L., Robert, D. 1988. Characterization of lignin by $1 \mathrm{H}$ and $13 \mathrm{C}$ NMR spectroscopy. Methods in Enzymology 161: 137-174.

Choi, J.H., Park, S.Y., Kim, J.H., Cho, S.M., Jang, S.K., Hong, C.Y., Choi, I.G. 2019. Selective deconstruction of hemicellulose and lignin with producing derivatives by sequential pretreatment process for biorefining concept. Bioresource Technology 291: 121913.

Doherty, W.O.S., Mousavioun, P., Fellows, C.M. 2011. Value-adding to cellulosic ethanol: Lignin polymers. Industrial Crops and Products 33(2): 259-276.

Helander, M., Theliander, H., Lawoko, M., Henriksson, G., Zhang, L., Lindstrom, M.E. 2013. Fractionation of technical lignin: Molecular mass and $\mathrm{pH}$ effects. Bioresources 8(2): 2270-2282.

Humpert, D., Ebrahimi, M., Czermak, P. 2016. Membrane technology for the recovery of lignin: A review. Membranes (Basel) 6(3): 42.

Jiang, X., Savithri, D., Du, X., Pawar, S., Jameel, H., Chang, H.-m., Zhou, X. 2016. Fractionation and characterization of kraft lignin by sequential precipitation with various organic solvents. ACS Sustainable Chemistry \& Engineering 5(1): 835842.

Kim, J.C., Choi, J.H., Kim, J.H., Cho, S.M., Park, S.W., Cho, Y.M., Park, S.Y., Kwak, H.W., Choi, I.G. 2020. Development of lignin-based polycarboxylates as a plasticizer for cement paste via peracetic acid oxidation. Bioresources 15(4): 8133-8145.

Kim, J.Y., Park, S.Y., Lee, J.H., Choi, I.G., Choi, J.W. 2017. Sequential solvent fractionation of lignin for selective production of monoaromatics by $\mathrm{Ru}$ catalyzed ethanolysis. RSC Advances 7(84): 5311753125.

Kim, J.Y., Heo, S.J., Park, S.Y., Choi, I.G., Choi, J.W. 2017. Selective production of monomeric phenols from lignin via two-step catalytic cracking process. Journal of the Korean Wood Science and
Technology 45(3): 278-287.

Lee, H.W., Jeong, H.S., Ju, Y.M., Yoo, W.J., Lee, J.J., Lee S.M. 2019. Pyrolysis properties of lignins extracted from different biorefinery process. Journal of the Korean Wood Science and Technology 47(4): 486-497.

Leskinen, T., Kelley, S.S., Argyropoulos, D.S. 2015. Refining of ethanol biorefinery residues to isolate value added lignins. ACS Sustainable Chemistry \& Engineering 3(7): 1632-1641.

Li, M.-F., Sun, S.-N., Xu, F., Sun, R.-C. 2012. Sequential solvent fractionation of heterogeneous bamboo organosolvlignin for value-added application. Separation and Purification Technology 101: 18-25.

Lisperguer, J., Perez, P., Urizar, S. 2009. Structure and thermal properties of lignins: Characterization by infrared spectroscopy and differential scanning calorimetry. Journal of the Chilean Chemical Society 54(4): 460-463.

Lourençon, T.V., Hansel, F.A., da Silva, T.A., Ramos, L.P., de Muniz, G.I.B., Magalhães, W.L.E. 2015. Hardwood and softwood kraft lignins fractionation by simple sequential acid precipitation. Separation and Purification Technology 154: 82-88.

Mohamed Saraya, E. S., Hanaa Rokbaa, A.L. 2016. Preparation of vaterie calcuim carbonate in the form of spherical nanopaticales with the aid of polycarboxylate superplasticizer as a capping agent. American Journal of Nanomaterials 4(2): 44-51.

Mörck, R., Yoshida, H., Kringstad, K.P., Hatakeyama, H. 1986. Fractionation of kraft lignin by successive extraction with organic solvents. 1. Functional groups (13) C-NMR-spectra and molecular weight distributions. Holzforschung 40: 51-60.

Park, S.Y., Kim, J.Y., Youn, H.J., Choi, J.W. 2018. Fractionation of lignin macromolecules by sequential organic solvents systems and their characterization for further valuable applications. International Journal of Biological Macromolecules 106: 793 - 
802.

Park, S.Y., Cho, S.M., Kim, J.C., Hong, C.Y., Kim, S.H., Ryu. G.H., Choi, I.G. 2019. Effect of peracetic acid and hydrogen peroxide concentration on kraft lignin degradation at room temperature. Bioresources 14(2): 4413-4420.

Park, S.Y., Choi, J.H., Kim, J.H., Cho, S.M., Yeon, S.H., Jeong, H.S., Lee, S.M., Choi, I.G. 2020. Peracetic acid-induced kraft lignin solubilization and its characterization for selective production of macromolecular biopolymers. ýlnternational Journal of Biological Macromolecules 161(15): 1240-1246

Ragauskas, A.J., Beckham, G.T., Biddy, M.J., Chandra, R., Chen, F., Davis, M.F., Davison, B.H., Dixon, R.A., Gilna, P., Keller, M., Langan, P., Naskar, A.K., Saddler, J.N., Tschaplinski, T.J., Tuskan, G.A., Wyman, C.E. 2014. Lignin valorization: Improving lignin processing in the biorefinery. Science 344(6185): 1246843.

Sameni, J., Krigstin, S., Sain, M. 2017. Solubility of lignin and acetylated lignin in organic solvents. Bioresources 12(1): 1548-1565.

Sills, D.L., Gossett, J.M. 2012. Using FTIR to predict saccharification from enzymatic hydrolysis of alkali-pretreated biomasses. Biotechnology and Bioengineering 109(2): 353-362.

Strassberger, Z., Tanase, S., Rothenberg, G. 2014. The pros and cons of lignin valorisation in an integrated biorefinery. RSC Advances 4(48): 25310-25318.

Sun, R.C., Tomkinson, J., Bolton, J. 1999. Effects of precipitation $\mathrm{pH}$ on the physico-chemical properties of the lignins isolated from the black liquor of oil palm empty fruit bunch fibre pulping. Polymer Degradation and Stability 63: 195-200.

Terashima, N., Hafren, J., Westermark, U., VanderHart, D.L. 2002. Nondestructive analysis of lignin struc- ture by NMR spectroscopy of specifically 13Cenriched lignins. Holzforschung 56(1): 43-50.

Toledano, A., García, A., Mondragon, I., Labidi, J. 2010. Lignin separation and fractionation by ultrafiltration. Separation and Purification Technology 71(1): 38-43.

Thring, R.W., Vanderlaan, M.N., Griffin, S.L. 1996. Fractionation Of Alcell@ lignin by sequential solvent extraction. Journal of Wood Chemistry and Technology 16(2): 139-154.

Vishtal, A., Kraslawski, A. 2011. Challenges in industrical applications of technical lignins. Bioresources 6(3): 3547-3568.

Wang, K., Xu, F., Sun, R. 2010. Molecular characteristics of kraft-AQ pulping lignin fractionated by sequential organic solvent extraction. International Journal of Molecular Sciences 11(8): 2988-3001.

Wen, J.L., Sun, S.L., Xue, B.L., Sun, R.C. 2013. Recent advances in characterization of lignin polymer bysolution-state Nuclear Magnetic Resonance (NMR) methodology. Materials (Basel) 6(1): 359391.

Zhang, T., Gao, J., Qi, B., Liu, Y. 2014. Performance of concrete made with superplasticizer from modified black liquor and polycarboxylate. Bioresources 9(4): 7351-7362.

Zhou, G., Taylor, G., Polle, A. 2011. FTIR-ATR-based prediction and modeling of lignin and energy contents reveals independent intra-specific variation of these traits in bioenergy poplars. Plant Methods 7(9): 1-10.

Zhu, W., Theliander, H. 2015. Precipitation of lignin from softwood black liquor: An investigation of the equilibrium and molecular properties of lignin. Bioresources 10(1): 1696-1714. 